\title{
ANALISIS KUALITAS PELAYANAN LABORATORIUM TERHADAP KEPUASAN MAHASISWA PENDIDIKAN BIOLOGI FKIP UNTAN
}

\author{
Eka Ariyati \\ Prodi Pendidikan Biologi, FKIP Untan, Pontianak \\ Email: eka.ariyati@fkip.untan.ac.id
}

\begin{abstract}
This research aimed to analyze student's satisfaction on the quality of laboratory services in Biology Education. The exploratory research was used in this research. The subjects in this research are Biology Education's students of FKIP Tanjungpura University. The data were collected using questionnaire with Likert scale. Data were analyzed to reveal the picture on the ground that were collected descriptively by interpreting the results of data processing through the tabulation. The results of this research are: (1) The level of students's satisfaction to the services of laboratory/laboratory staff in the amount of $41.24 \%$ stated quite satisfied, $42.27 \%$ are satisfied, and $11.34 \%$ are very satisfied; (2) The level of students's satisfaction to the service of lab assistant in the amount of $40.21 \%$ stated quite satisfied, $40.21 \%$ are satisfied, and $12.37 \%$ are very satisfied; (3) The level of students's satisfaction to the equipment in the lab in the amount of $58.76 \%$ stated quite satisfied, $21.66 \%$ are satisfied, and $2.06 \%$ are very satisfied; (4) The level of students's satisfaction to the lab materials in the amount of $52.58 \%$ stated quite satisfied, $22.68 \%$ are satisfied, and $2.06 \%$ are very satisfied; (5) The level of students's satisfaction to the physical facilities and supporting laboratories in the amount of $46.39 \%$ stated quite satisfied, $22.68 \%$ are satisfied, and 5:15\% very satisfied. Overall the level of student's satisfaction to the laboratory services of Biology Education in FKIP Tanjungpura University is quite satisfied.
\end{abstract}

Keywords: student's satisfaction, laboratory services, quite satisfied.

\section{PENDAHULUAN}

Lembaga Pendidikan Tinggi tumbuh dan berkembang sebagaimana layaknya industri jasa, dan setiap saat berubah seiring dengan proses globalisasi, oleh karenanya perlu dipasarkan dan berorientasi kepada mahasiswa sebagai salah satu pelanggan atau penggunanya. Upaya memenuhi keinginan mahasiswa dan calon mahasiswa merupakan kunci sukses memenangkan persaingan (Simonson, 1993). Tindakan terbaik yang perlu dilakukan oleh lembaga pendidikan tinggi adalah menggunakan umpan balik dari mahasiswa atau calon mahasiswa untuk mengendalikan perubahan organisasional (Bergin, 1997). Kesesuaian antara keinginan atau persepsi konsumen (customer voice) dan kehendak organisasi pengelola perguruan tinggi (company voice) merupakan syarat penting keberhasilan proses pendidikan tinggi (Muafi dan Yuni Siswanti, 2007).

Peningkatan kualitas pendidikan dilakukan sejalan dengan perkembangan dan tuntutan terhadap lulusan yang berkompeten dalam bidang yang ditekuni. Laboratorium merupakan sarana penunjang pendidikan yang harus dimiliki oleh lembaga pendidikan. Perguruan tinggi merupakan jenjang pendidikan yang mencetak agent of change bagi pembangunan pendidikan harus senantiasa memperbaiki sistem pendidikan untuk menciptakan mutu pendidikan yang diharapkan. Salah satu sarana akademik yang dibutuhkan untuk mendukung pelaksanaan kegiatan belajar mengajar di perguruan tinggi diperlukan adanya sarana berupa laboratorium. Laboratorium merupakan unsur penting sebagai sarana penunjang kegiatan ilmiah. 
Laboratorium Pendidikan Biologi telah mengupayakan memberikan layanan untuk memenuhi kebutuhan mahasiswa dan dosen akan fasilitas laboratorium (ruang laboratorium, alat, dan bahan praktikum), sumber belajar (buku, kamus, ensiklopedi, jurnal ilmiah), dan sarana yang lainnya (komputer, laptop, TV), namun dalam perjalanannya sering mendapat keluhan dari mahasiswa dan dosen. Keluhankeluhan yang sering mucul yaitu tentang asisten praktikum yang mengganti jadwal, petugas laboratorium tidak ada di tempat saat diperlukan. Alat yang tidak optimal dalam penggunaan juga menjadi keluhan mahasiswa. Keluhan yang muncul dari mahasiswa hampir sama dengan keluhan yang disampaikan oleh dosen. Di samping itu keluhan yang muncul, ditengarai dari prosedur peminjaman sarana laboratorium. Pengukuran kepuasan pelanggan merupakan elemen penting dalam menyediakan pelayanan yang lebih baik, lebih efisien dan lebih efektif. Apabila mahasiswa merasa tidak puas terhadap suatu pelayanan yang disediakan, maka pelayanan tersebut dapat dipastikan tidak efektif dan tidak efisien.

Di satu pihak permintaan mahasiswa dan dosen akan layanan laboratorium semakin meningkat, namun kualitas pelayanan yang diberikan ditengarai belum sebanding dengan pemenuhan permintaan mahasiswa dan dosen tersebut. Penanganan keluhan memberikan peluang untuk mengubah seorang pelanggan (mahasiswa dan dosen) tidak puas menjadi pelanggan yang puas. Proses penanganan keluhan yang efektif mulai identifikasi disertai dengan penentuan sumber yang menyebabkan pelanggan tidak puas dan mengeluh. Menurut Tjiptono (1997) paling tidak ada empat aspek untuk menangani keluhan, yaitu: (1) empati terhadap pelanggan yang marah; (2) kecepatan dalam penanganan keluhan; (3) kewajaran atau keadilan dalam memecahkan permasalahan atau keluhan; dan (4) kemudahan bagi konsumen untuk menghubungi lembaga. Terciptanya kualitas pelayanan tentunya akan menciptakan kepuasan terhadap pengguna layanan.

Pelayanan kepada mahasiswa bisa dikatakan baik (profesionalisme) bila mahasiswa dapat dengan mudah mendapatkan pelayanan dan dengan prosedur yang tidak panjang, waktu cepat dan hampir tidak ada keluhan yang diberikan kepadanya. Kondisi tersebut dapat terwujud bilamana laboratorium Pendidikan Biologi FKIP Universitas Tanjungpura didukung oleh sumber daya manusia yang mumpuni baik dari kualitas maupun kuantitas, disamping juga adanya sumber daya peralatan dan sumber daya keuangan yang memadai.

Karena kualitas pelayanan mengacu pada jasa, maka penulis hendak membahas mengenai jasa. Dimana jasa adalah proses atau aktivitas yang tidak berwujud dan menunjukkan interaksi antar manusia, meskipun pihak-pihak yang terlibat tidak menyadarinya. Namun hasil dari jasa tidak menyebabkan kepemilikan individu yang terlibat. Makna dari jasa berkaitan dengan kualitas, berarti kesesuaian suatu produk baik barang maupun jasa dengan tujuan yang telah ditentukan, dimana kehandalan, ketahanan, dan waktu yang tepat dalam memaknai integritas, sehingga dapat memuaskan pelanggan. Dengan demikian kualitas jasa adalah usaha pemenuhan kebutuhan dan keinginan pelanggan serta ketepatan penyampaian jasa, agar layanan yang mereka terima sesuai dengan harapan / keinginan pelanggan (Agustiono dan Sumarno, 2006).

Laboratorium/studio adalah sarana penunjang jurusan dalam studi yang bersangkutan, dan sumber unit daya dasar untuk pengembangan ilmu dan pendidikan. Dalam pendidikan laboratorium adalah tempat proses belajar mengajar melalui metode praktikum yang dapat menghasilkan praktikum hasil pengalaman belajar. Dimana mahasiswa berinteraksi dengan berbagai alat dan bahan untuk mengobservasi gejala-gejala yang dilengkapinya secara langsung. Praktikum didalam pendidikan dapat diartikan sebagai suatu metode mendidik untuk belajar dan mempraktekkan segala aktifitas dalam proses belajar mengajar untuk menguasai suatu keahlian (Kemendikbud Nomor 134, 1983). Laboratorium memiliki beberapa fungsi dalam proses pendidikan, yakni:

1. Sebagai tempat untuk berlatih mengembangkan keterampilan intelektual melalui kegiatan pengamatan, pencatatan dan pengkaji gejala-gejala alam.

2. Mengembangkan keterampilan motorik siswa. 
3. Memberikan dan memupuk keberanian untuk mencari hakekat kebenaran ilmiah dari sesuatu objek dalam lingkungan alam dan sosial.

4. Memupuk rasa ingin tahu siswa sebagai modal sikap ilmiah seseorang calon ilmuan.

5. Membina rasa percaya diri sebagai akibat keterampilan dan pengetahuan atau penemuan yang diperolehnya (Sukarso, 2005).

Kualitas pelayanan didefinisikan sebagai penilaian pelanggan atas keunggulan atau keistimewaan suatu produk atau layanan secara menyeluruh (Zeithaml dalam Prasetyaningrum, 2009). Apabila kinerja pelayanan dikaitkan dengan harapan (expectation) dan kepuasan (satisfaction) maka gambarannya adalah sebagai berikut (Barata, 2006):

1. Kinerja < Harapan (Performance < Expectation)

2. Bila kinerja layanan menunjukkan keadaan di bawah harapan pelanggan, maka pelayanan kepada pelanggan dapat dianggap tidak memuaskan.

3. Kinerja $=$ Harapan (Performance $=$ Expectation)

4. Bila kinerja layanan menunjukkan sama atau sesuai dengan harapan pelanggan, maka pelayanan dianggap memuaskan, tetapi tingkat kepuasannya minimal karena pada keadaan seperti ini dapat dianggap belum ada keistimewaan layanan. Jadi pelayanan dianggap biasa atau wajar-wajar saja.

5. Kinerja > Harapan (Performance > Expectation)

6. Bila kinerja layanan menunjukkan lebih dari harapan pelanggan, maka pelayanan dianggap istimewa atau sangat memuaskan, karena pelayanan yang diberikan ada pada tahap yang optimal.

Tse dan Wilton (1998) dalam Kandampully dan Suhartanto (2000) mendefinisikan kepuasan konsumen sebagai respon konsumen terhadap evaluasi diskrepansi/ketidaksesuaian yang dirasakan antara ekspektasi sebelumnya (atau beberapa norma kinerja lain) dan kinerja aktual dari produk sebagaimana yang dirasakan setelah pengkonsumsiannya.

Kepuasan atau ketidakpuasan pelanggan adalah respon pelanggan terhadap evaluasi ketidaksesuaian yang dirasakan antara harapan sebelumnya dan kinerja aktual produk yang dirasakan setelah pemakaiannya (Tjiptono, 1997). Untuk mempertahankan kepuasan pelanggan, organisasi jasa harus melakukan 4 hal, yaitu mengidentifikasi setiap pelanggannya, memahami tingkat harapan pelanggan atas kualitas pelayanan, memahami strategi kualitas pelayanan pelanggan, dan memahami siklus pengukuran serta umpan balik dari kepuasan pelanggan (Tjiptono, 1997 dalam Agustiono dan Sumarno, 2006).

\section{METODE PENELITIAN}

\section{Jenis Penelitian}

Penelitian ini merupakan penelitian kualitatif. Metode yang adalah metode deskriptif. Jenis penelitian yang digunakan adalah penelitian eksploratori.

\section{Subjek Penelitian}

Subjek dalam penelitian ini adalah mahasiswa Program Studi Pendidikan Biologi FKIP Universitas Tanjungpura. Subjek dalam penelitian ini diambil dengan beberapa pertimbangan diantaranya, yaitu: (1) adanya keterbatasan waktu yang dimiliki oleh peneliti, (2) dapat memper cepat proses pelaksanaan penelitian, dan (3) memperoleh hasil penelitian yang dapat dianggap tepat (akurat karena wilayah penelitian yang dibatasi akan lebih memungkinkan peneliti dapat memperoleh dan mengolah data lebih detail. 
Tabel 1. Jadwal Penelitian

\begin{tabular}{|c|c|c|c|c|c|}
\hline \multirow{2}{*}{ No } & \multirow{2}{*}{ Jenis Kegiatan } & \multicolumn{4}{|l|}{ Bulan } \\
\hline & & 12 & 3 & 4 & 5 \\
\hline 1 & $\begin{array}{l}\text { Studi Pendahuluan dan Penyu-sunan } \\
\text { Proposal }\end{array}$ & & & & \\
\hline 2 & Pembuatan instrumen/alat pengumpul data & & & & \\
\hline 3 & Validasi instrumen/alat pengumpul data & & & & \\
\hline 4 & Revisi instrumen/alat pengumpul data & & & & \\
\hline 5 & Pengambilan dan pengumpulan data & & & & \\
\hline 6 & Analisis Data & & & & \\
\hline 7 & Pelaporan & & & & \\
\hline
\end{tabular}

Teknik dan Alat Pengumpulan Data

Alat pengumpul data yang digunakan dalam penelitian ini adalah angket. Angket menggunakan skala Likert, di mana jawaban setiap item instrumen yang menggunakan skala likert mempunyai gradasi positif sampai negatif.

Tabel 2. Kriteria Penilaian Tingkat Kepuasan

\begin{tabular}{lc}
\hline Keterangan & Bobot \\
\hline Sangat Puas (SP) & 5 \\
\hline Puas (P) & 4 \\
\hline Cukup Puas (CP) & 3 \\
\hline Kurang Puas (KP) & 2 \\
\hline Sangat Tidak Puas (STP) & 1 \\
\hline
\end{tabular}

\section{Analisis Data}

Analisis data yang dilakukan ini berdasarkan tujuan yang akan dicapai, yaitu untuk menganalisis kepuasan mahasiswa terhadap layanan laboratorium Pendidikan Biologi FKIP Universitas Tanjungpura. Data dianalisis untuk mengungkapkan gambaran yang ada di lapangan yang terkumpul secara deskriptif dengan cara menginterpretasikan hasil pengolahan data melalui tabulasi.
Menurut J. Supranto (2003), penggo-longan kategori tiap indikator dihitung berdasarkan nilai yang diperoleh dari hasil angket dengan cara mengalikan besar bobot (nilai) pada kategori tertentu yang telah ditetapkan dengan jumlah responden yang menjawab masing-masing kategori tersebut. Berdasarkan data, dengan 97 responden, maka dapat ditentukan bobot penilaian dengan menggunakan jarak yang dapat dihitung melalui nilai tertinggi dan nilai terendah sebagai berikut :

Jarak = jarak tertinggi - jarak terendah

Nilai tertinggi $=$ total responden $\mathrm{x}$ bobot terbesar

Nilai terendah $=$ total responden $\mathrm{x}$ bobot terkecil

Interval $\quad=$ Jarak / Banyaknya kelas

\section{HASIL DATA DAN PEMBAHASAN \\ Hasil Penelitian \\ Laboran/Staf Laboratorium}

Hasil analisis deskriptif untuk 6 item mengenai laboran/staf laboratorium dari 97 responden dapat dilihat pada tabel 3.

Tabel 3. Hasil Deskriptif Faktor Layanan Laboran/Staf Laboratorium

\begin{tabular}{lllcc}
\hline No & Interval & Jawaban & Frekuensi & Persentase \\
\hline $\mathbf{1}$ & $6-10$ & Sangat Tidak Puas & 1 & 1,03 \\
\hline $\mathbf{2}$ & $11-15$ & Tidak Puas & 4 & 4,12 \\
\hline $\mathbf{3}$ & $16-20$ & Cukup Puas & 40 & 41,24 \\
\hline $\mathbf{4}$ & $21-25$ & Puas & 41 & 42,27 \\
\hline $\mathbf{5}$ & $26-30$ & Sangat Puas & 11 & 11,34 \\
\hline Jumlah & & $\mathbf{9 7}$ & $\mathbf{1 0 0}$ \\
\hline
\end{tabular}


Dari tabel di atas terlihat 42,27\% responden menyatakan puas terhadap layanan yang diberikan oleh laboran/staf laboratorium. Dengan demikian mahasiswa memandang layanan dari pihak laboran/ staf laboratorium cukup baik dan perlu ditingkatkan.

\section{Asisten Praktikum}

Hasil analisis deskriptif untuk 7 item mengenai asisten praktikum dari 97 responden dapat dilihat pada tabel 4 .

Tabel 4. Hasil Deskriptif Faktor Layanan Asisten Praktikum

\begin{tabular}{lllll}
\hline No & Interval & Jawaban & Frekuensi & Persentase \\
\hline $\mathbf{1}$ & $7-12$ & Sangat Tidak Puas & 1 & 1,03 \\
\hline $\mathbf{2}$ & $13-18$ & Tidak Puas & 6 & 6,18 \\
\hline $\mathbf{3}$ & $19-24$ & Cukup Puas & 39 & 40,21 \\
\hline $\mathbf{4}$ & $25-30$ & Puas & 39 & 40,21 \\
$\mathbf{5}$ & $31-36$ & Sangat Puas & 12 & 12,37 \\
\hline
\end{tabular}

Dari tabel di atas terlihat $40,21 \%$ responden menyatakan puas terhadap layanan yang diberikan oleh asisten praktikum. Dengan demikian mahasiswa memandang layanan dari pihak asisten praktikum cukup baik dan perlu ditingkatkan.

\section{Peralatan}

Hasil analisis deskriptif untuk 4 item mengenai peralatan laboratorium dari 97 responden dapat dilihat pada tabel 5 .

Tabel 5. Hasil Deskriptif Faktor Peralatan Laboratorium

\begin{tabular}{lllcc}
\hline No & Interval & Jawaban & Frekuensi & Persentase \\
\hline 1 & $7-12$ & Sangat Tidak Puas & 1 & 1,03 \\
\hline 2 & $13-18$ & Tidak Puas & 16 & 16,49 \\
\hline 3 & $19-24$ & Cukup Puas & 57 & 58,76 \\
\hline 4 & $25-30$ & Puas & 21 & 21,66 \\
\hline 5 & $31-36$ & Sangat Puas & 2 & 2,06 \\
\hline Jumlah & & $\mathbf{9 7}$ & $\mathbf{1 0 0}$ \\
\hline
\end{tabular}

Dari tabel di atas terlihat $58,76 \%$ responden menyatakan cukup puas terhadap peralatan yang terdapat di laboratorium pendidikan biologi. Dengan demikian mahasiswa memandang peralatan yang ada cukup dan perlu ditingkatkan kuantitas dan kualitasnya.

\section{Bahan}

Hasil analisis deskriptif untuk 1 item mengenai bahan praktikum dari 97 responden dapat dilihat pada tabel 6 .

Tabel 6. Hasil Deskriptif Faktor Bahan di Laboratorium

\begin{tabular}{|c|c|c|c|}
\hline Interval & Jawaban & Frekuensi & Persentase \\
\hline 1 & Sangat Tidak Puas & 3 & 3,09 \\
\hline 2 & Tidak Puas & 19 & 19,59 \\
\hline 3 & Cukup Puas & 51 & 52,58 \\
\hline 4 & Puas & 22 & 22,68 \\
\hline 5 & Sangat Puas & 2 & 2,06 \\
\hline Jumlah & & 97 & 100 \\
\hline
\end{tabular}

Dari tabel di atas terlihat 52,58\% responden menyatakan cukup puas terhadap bahan-bahan praktikum yang terdapat di laboratorium pendidikan biologi. Dengan demikian mahasiswa memandang bahan yang ada cukup untuk menunjang kegiatan praktikum. 


\begin{abstract}
Fasilitas Fisik dan Penunjang mengenai fisik dan fasilitas penunjang di Laboratorium

Hasil analisis deskriptif untuk 6 item laboratorium dari 97 responden dapat dilihat pada tabel 7.
\end{abstract}

Tabel 7. Hasil Deskriptif Faktor Fasilitas Fisik dan Penunjang Laboratorium

\begin{tabular}{lllcc}
\hline No & Interval & Jawaban & Frekuensi & Persentase \\
\hline 1 & $6-10$ & Sangat Tidak Puas & 5 & 5,15 \\
\hline 2 & $11-15$ & Tidak Puas & 20 & 20,63 \\
\hline 3 & $16-20$ & Cukup Puas & 45 & 46,39 \\
\hline 4 & $21-25$ & Puas & 22 & 22,68 \\
\hline 5 & $26-30$ & Sangat Puas & 5 & 5.15 \\
\hline Jumlah & & $\mathbf{9 7}$ & $\mathbf{1 0 0}$ \\
\hline
\end{tabular}

Dari tabel di atas terlihat $46,39 \%$ responden menyatakan cukup puas terhadap fasilitas fisik dan penunjang di laboratorium pendidikan biologi.

\section{Pembahasan}

Pengukuran terhadap kepuasan pelanggan merupakan elemen penting dalam menyediakan pelayanan yang lebih baik, lebih efisien dan lebih efektif. Suatu pelayanan dinilai memuaskan bila pelayanan tersebut dapat memenuhi kebutuhan dan harapan pelanggan. Apabila pelanggan merasa tidak puas terhadap suatu pelayanan yang disediakan, maka pelayanan tersebut dapat dipastikan tidak efektif dan tidak efisien. Hal ini terutama sangat penting bagi pelayanan publik. Ukuran kepuasan pelanggan dapat dipandang dari dua perspektif yaitu dari sisi tingkat pelayanan yang diberikan dan dari sisi pemberi pelayan dalam memberikan pelayanan.

Dari hasil analisis kepuasan mahasiswa terhadap pelayanan laboratorium pendidikan biologi ada 5 faktor yang yang muncul, yaitu 1) layanan dari laboran/staf laboratorium, 2) layanan dari asisten praktikum, 3) peralatan laboratorium, 4) bahan-bahan praktikum, dan 5) fasilitas fisik dan penunjang laboratorium. Tingkat kepuasan mahasiswa dari kelima faktor tersebut berada pada kategori cukup puas.

Tingkat kepuasan mahasiswa terhadap layanan laboran/staf laboratorium.

Tingkat kepuasan mahasiswa terhadap layanan dari laboran/staf laboratorium adalah $41,24 \%$ menyatakan cukup puas, $42,27 \%$ puas, dan 11,34\% sangat puas. Dari hasil analisis, responden menyatakan bahwa laboran/staf laboratorium sudah baik dalam memberikan pelayanan kepada mahasiswa. Namun, responden menyarankankan perlunya penambahan staf laboratorium seperti teknisi yang bertugas untuk memantau dan memelihara peralatan yang ada, petugas kunci pintu laboratorium dan ruang lainnya serta staf administrasi. Selain itu, responden mengharapkan agar skill/keterampilan dari laboran/staf yang ada dapat ditingkatkan termasuk sikap keramahtamahan.

Saat ini laboratorium pendidikan biologi hanya memiliki 1 orang petugas sesuai Surat Perjanjian Kontrak yang diberi tugas sebagai laboran. Laboran adalah petugas non dosen yang membantu dosen untuk melaksanakan kegiatan praktikum/peragaan (meliputi penyiapan bahan, membantu pelaksanaan praktikum). Laboran juga dapat dikatakan sebagai Tenaga Kependidikan yang bekerja di laboratorium dan membantu proses belajar mengajar mahasiswa vokasi dan akademik Strata 1, 2 dan 3, serta penelitian dosen.

Keberadaan laboran di suatu laboratorium sangatlah penting dalam menentukan keberhasilan akademik dosen dan mahasiswa. Laboran seyogyanya memiliki hard skills dan soft skills yang memadai. Inisiatif, ketekunan, kreatifitas, kecakapan, dan keterampilan serta pengetahuan yang dikuasai laboran membantu efisiensi dan efektifitas serta produktifitas dari laboaratorium yang dikelola perguruan tinggi (Prihantoro, 2013). Hal ini juga menjadi catatan dari responden dan menyarankan agar laboran yang ada di laboratorium pendidikan biologi 
meningkatkan keterampilannya agar dapat memberikan informasi dengan cepat dan tepat yang berkaiatan dengan penggunaan alat. Selain itu responden mengharapkan agar keramah tamahan ditingkatkan lagi.

Petugas laboratorium tidak hanya laboran, sebaiknya juga memiliki teknisi dan analis yang bisa membantu kelancaran kegiatan di laboratorium. Keterbatasan sumber daya manusia yang ada di laboratorium pendidikan biologi juga menjadi salah satu kendala. Hal ini berdampak pada layanan yang diberikan kepada pengguna atau mahasiswa. Selain itu ketiadaan teknisi mempengaruhi kondisi peralatan yang ada karena tidak bisa dilakukan maintenance secara berkala.

\section{Tingkat kepuasan mahasiswa terhadap layanan asisten praktikum}

Asisten praktikum adalah mahasiswa yang telah melalui proses seleksi asisten yang diberi tugas untuk mendampingi mahasiswa dalam pelaksanaan praktikum. Dalam prosesnya asisten praktikum akan mendapat arahan dari dosen mata kuliah serta bantuan teknisi dan laboran di laboratorium.

Dari hasil analisis, 40,20\% responden menyatakan puas terhadap layanan asisten praktikum mata kuliah dan $12,37 \%$ sangat puas. Hal ini mengindikasikan bahwa asisten praktikum sudah memberikan layanan dengan baik kepada mahasiswa namun masih perlu adanya perbaikan dan peningkatan kinerjanya. Beberapa saran disampaikan oleh responden terkait dengan asisten praktikum, yaitu: 1) keramahtamahan ditingkatkan lagi terutama dalam memberikan bantuan selama praktikum; 2) lebih menguasai materi dan penggunaan alat agar memudahkan dalam memberikan infor-masi; 3) sebelum praktikum asisten dapat mempersiapkan alat yang diperlukan untuk melakukan praktikum secara lengkap agar praktikum dapat berjalan dengan lancar; 4) asisten sebaiknya memperhatikan praktikan agar giliran dalam bekerja tidak sibuk sendiri; 5) asisten lebih tepat waktu dalam praktikum agar dapat menjadi contoh yang baik untuk praktikan; 6) ketepatan waktu dalam mengo-reksi laporan dan kehadiran asisten pada setiap kegiatan praktikum; 7) asisten sebaiknya memberikan koreksian pada laporan praktikan lebih rapi lagi agar tidak terlalu mencoret coret laporan praktikan; 8) laporan sebaiknya dibagikan satu minggu setelah laporan dikumpulkan agar praktikan tahu dan dapat memperbaiki kesalahan di laporan selanjutnya; 9) jika ada praktikum di hari dan jam yang berbeda atau diganti hari sebaiknya asisten hadir semua dan mendampingi hingga selesai; dan 10) asisten lebih sabar dalam menghadapi praktikan dan tidak mudah cepat emosi. Saran dari responden di atas pada dasarnya merupakan tugas dan kewajiban dari asisten praktikum.

\section{Tingkat kepuasan mahasiswa terhadap peralatan laboratorium}

Peralatan laboratorium adalah alat-alat yang digunakan untuk keperluan kegiatan di laboratorium, baik laboratorium di sekolah, universitas, pusat penelitian, rumah sakit, klinik atau laboratorium lainnya. Alat laboratorium biasanya dibuat dengan bahan atau material yang khusus sesuai dengan tujuan penggunaaan alat tersebut, karena alat laboratorium memerlukan daya tahan yang baik serta hasil yang baik pula.

Bahan alat laboratorium ada yang terbuat dari bahan kaca atau glass, metal, plastik dan lain sebagainya sesuai dengan kebutuhan, bahkan ada yang merupakan gabungan dari berbagai material. Memilih alat laboratorium yang hendak digunakan harus sesuai dengan kebutuhan, karena setiap alat telah dibuat sesuai dengan fungsinya masing-masing. Jenisnya sangat banyak, sehingga di dalam sebuah laboratorium akan sangat banyak ditemukan alat-alat sesuai dengan fungsinya masing-masing.

Dari hasil analisis mengenai peralatan di laboratorium pendidikan biologi, sebagian besar responden baru menyatakan cukup puas $(58,76 \%)$. Hal ini disebabkan beberapa hal, antara lain: 1) ada peralatan yang jumlahnya tidak sebanding dengan jumlah praktikan, 2) ada peralatan yang rusak dan perlu diganti, 3) beberapa alat perlu maintenance dan kalibrasi secara berkala. Hal senada juga disarankan oleh para responden. Selain itu, kendala lain yang dihadapi dalam penyediaan peralatan laboratorium adalah masalah dana. Selama ini, peralatan yang ada berasal dari 
dana APBN yang terbatas dalam pengajuannya. Kede-pannya perlu dipikirkan proses pengadaan alat laboratorium termasuk penambahan jumlah peralatan yang sudah ada agar dapat mendukung semua kegiatan yang dilakukan.

\section{Tingkat kepuasan mahasiswa terhadap bahan praktikum}

Bahan yang digunakan dalam kegiatan di laboratorium biologi dapat berupa bahan kimia, bahan alami (berupa benda dan makhluk hidup). Bahan kimia yang berbahaya dengan ciri mudah terbakar, mudah meledak, korosif dan beracun. Contoh bahan kimia berbahaya seperti asam khlorida, asam sulfat dan asam phosphat. Bahan kimia yang kurang berbahaya seperti aquadest, amilum, yodium dan gula.

Bahan dari makhluk hidup yang digunakan di laboratorium biologi, untuk pengujian/ pembuktian seperti bahan makanan, bagian tumbuhan (bunga, daun, buah, batang dan akar), bagian hewan (bulu, rambut, tulang, darah dsb), mikroorganisme (bakteri, ganggang, jamur, kultur Amoeba proteus dsb).

Dari hasil analisis angket mengenai ketersediaan bahan di laboratorium biologi untuk pelaksanaan praktikum maupun penyelesaian tugas akhir direspon dengan kategori cukup puas sebesar $52,58 \%$ dan kategori puas hanya $22,68 \%$. Responden menyarankan agar jumlah bahan yang disediakan untuk kegiatan praktikum di laboratorium maupun di lapangan dapat ditambah jumlahnya untuk setiap kelompok. Selain itu, responden mengeluhkan saat harus mencari bahan sendiri untuk praktikum taksonomi dan anatomi hewan yang tidak ada disekitar kampus.

Pada dasarnya laboratorium sudah berusaha untuk menyiapkan bahan sesuai keperluaan dan ketersediaan yang ada. Perlu dilakukan inventarisasi bahan secara berkala untuk meminimalisir keluhan dari pengguna namun juga diperlukan dukungan dalam bentuk dana guna penyediaan bahan-bahan praktikum.

\section{Tingkat kepuasan mahasiswa terhadap fasilitas fisik dan penunjang laboratorium}

Fasilitas fisik dan penunjang laboratorium biologi mendapat respon yang beragam dari mahasiswa untuk masing-masing tingkat kepuasan. 5.15\% responden menyatakan sangat tidak puas, $20.63 \%$ tidak puas, $46.39 \%$ cukup puas, $22.68 \%$ puas, dan $5.15 \%$ sangat puas. Tingkat kepuasan mahasiswa tersebut dapat dimaklumi oleh peneliti karena laboratorium biologi masih minim dalam sisi fasilitas baik secara fisik maupun penunjang. Keterbatasan ruangan atau kecilnya ukuran yang di miliki oleh laboratorium biologi mengesankan penuh dengan alat dan bahan karena kesulitan dalam menata/ mensetting ruangan.

Dari angket yang diberikan, responden menyarankan agar: 1) fasilitas internet yang memadai (mudah untuk diakses) baik di laboratorium bawah maupun atas, 2) disediakan loker tempat penyimpanan tas untuk menghindari kehilangan/ pencurian barangbarang, 3) ketersediaan kipas angin perlu ditambah, 4) menyediakan pustaka/ referensi secara terbuka, 5) jumlah kursi praktikan perlu dicek supaya kegiatan dapat berjalan dengan lancar, dan 6) tempat mencuci/wastafel yang berfungsi hanya satu, sebaiknya dua agar lebih efisien.

Sebuah laboratorium sebaiknya memiliki fasilitas ruangan untuk kegiatan praktikum, kegiatan administrasi, pengelolaan laboratorium, penyimpanan alat dan bahan, ruang persiapan, dan ruangan untuk kegiatan pemeliharaan atau maintenance. Bentuk, ukuran, tata letak dan fasilitas dari setiap ruangan dirancang sedemikian rupa sehingga memungkinkan setiap kegiatan yang dilaksanakan di dalamnya berjalan dengan baik dan nyaman.

Dari lima aspek tentang kepuasan mahasiswa terhadap layanan laboratorium biologi secara kesuluruhan menyatakan cukup puas sehingga perlu pembenahan dan perbaikan di semua sisi. Tjiptono (1997) mengungkapkan bahwa kepuasan atau ketidakpuasan pelanggan adalah respon pelanggan terhadap evaluasi ketidaksesuaian yang dirasakan antara harapan sebelumnya dan kinerja aktual produk yang dirasakan setelah pemakaiannya. Untuk mempertahankan kepuasan pelanggan dalam hal ini adalah mahasiswa, laboratorium harus melakukan 4 hal, yaitu mengidentifikasi setiap pelanggannya, 
memahami tingkat harapan pelanggan atas kualitas pelayanan, memahami strategi kualitas pelayanan pelanggan, dan memahami siklus pengukuran serta umpan balik dari kepuasan pelanggan (Tjiptono, 1997 dalam Agustiono dan Sumarno, 2006).

\section{KESIMPULAN}

Dari deskripsi yang dipaparkan di atas dapat diambil kesimpulan mengenai kepuasan mahasiswa terhadap pelayanan laboratorium Pendidikan Biologi FKIPUniversitas Tanjungpura sebagai berikut: (1) Tingkat kepuasan mahasiswa terhadap pelayanan laboran/staf laboratorium sebesar $41,24 \%$ menyatakan cukup puas, $42,27 \%$ puas, dan 11,34\% sangat puas; (2) Tingkat kepuasan mahasiswa terhadap pelayanan asisten praktikum sebesar 40,21\% menyatakan cukup puas, $40,21 \%$ puas, dan $12,37 \%$ sangat puas; (3) Tingkat kepuasan mahasiswa terhadap peralatan di laboratorium sebesar 58,76\% menyatakan cukup puas, $21,66 \%$ puas, dan $2,06 \%$ sangat puas; (4) Tingkat kepuasan mahasiswa terhadap bahan praktikum sebesar 52,58\% menyatakan cukup puas, $22,68 \%$ puas, dan 2,06\% sangat puas; (5) Tingkat kepuasan mahasiswa terhadap fasilitas fisik dan penunjuang laboratorium sebesar $46,39 \%$ menyatakan cukup puas, $22,68 \%$ puas, dan $5.15 \%$ sangat puas.

\section{DAFTAR PUSTAKA}

Barata,Atep Adya. 2006. Dasar-Dasar Pelayanan

Prima. Cetakan Ketiga, November 2006, Jakarta: Gramedia.

Agustiono, Budi, dan Sumarno. 2006. Analisis

Pengaruh Kualitas Pelayanan Jasa terhadap Kepuasan dan Loyalitas Pasien Rawat Inap di Rumah Sakit St. Elisabeth Semarang, EKSPLANASI, Vol. 1, no. 1, April 2006, p. 1 - 18.

Bergin, Sarah. 1997. Communication is the Key to Customer Success, Transportation and Distribution, March: p. $82-84$.
Chandra, dkk. 2001. Analisis Kepuasan dan Loyalitas Konsumen terhadap Tingkat Penjualan di Warung Bu Kris (Studi Kasus pada Ayam Penyet sebagai Menu Unggulan Warung Bu Kris). Jurnal Manajemen dan Kewirausahaan. Vol. 3, no. 2, September 2001, p. $85-95$.

Engel, James F., Roger D. Blackwell, dan Paul W. Miniard. 1995. Perilaku Konsumen, Edisi Keenam, Jilid II. Jakarta: Binarupa Aksara.

Muafi dan Yuni Siswanti. 2007. Anteseden Ekuitas Merek Perguruan Tinggi: SEM dengan Pendekatan Two Step. Manajemen Usahawan Indonesia, no. 03, TH XXXVI, Maret, 2007, p.27 - 34 .

Prasetyaningrum, I.D. 2009. Analisis Pengaruh Pembelajaran dan KualitasPelayanan Terhadap Kepuasan Mahasiswa dan Loyalitas Mahasiswa (Studi Kasus Pada Undaris Ungaran). Tesis Universitas Diponegoro. Semarang: Tidak diterbitkan

Sandjaja, B. dan Heriyanto, A. 2011. Panduan Penelitian. Jakarta: Prestasi Pustaka.

Setyadin, B. 2003. Reduksi Data melalui Analisis Faktor Eksploratori. Makalah disajikan dalam Lokakarya Penelitian Kuantitatif di Malang tanggal 8-12 Desember 2003. Malang: Tidak diterbitkan.

Simonson, Itamar. 1993. Get Closer to Your Customers by Understanding How They Maker Choices. California Management Review (Summer): p.68 - 84.

Sugiono. 2006. Metode Penelitian Administrasi. Bandung: Alfabet.

Sukarso. 2005. Pengertian dan Fungsi Laboratorium. (Online http://wanmustafa. wordpress.com/ 2011/06/12/pengertian-danfungsi-laboratorium/, diakses pada tanggal 14 Juni 2016.

Syaodih, N. 2012. Metode Penelitian Pendidikan. Bandung: PT. Remaja Rosdakarya.

Tjiptono, F. 1997. Strategi Pemasaran, Jilid II. Yogyakarta: Andi Ofset. 
